\title{
Determination of Niobium and Tantalum in Titanium-Base Alloys
}

\author{
John L. Hague and Lawrence A. Machlan
}

\begin{abstract}
A procedure for the determination of niobium and tantalum in titanium-base alloys is described. The sample is dissolved in a mixture of hydrochloric and hydrofluoric acid, and oxidized with a minimum of nitric acid. The resulting solution is transferred to a column containing a strong quaternary amine anion-exchange resin (Dowex-1). Titanium and other alloying elements, except niobium and tantalum, are removed by elution with an ammonium chloride-hydrochloric-hydrofluoric acid solution. Niobium is removed by elution with an ammonium chloride-hydrofluoric acid solution. Tantalum is collected in a separate eluate of slightly acid ammonium chloride-ammonium fluoride solution. Boric acid is added to complex the fluoride, the earths acids precipitated with cupferron, ignited to the pentoxides, and weighed.
\end{abstract}

\section{Introduction}

One of the difficult problems of analytical chemistry has been the separation of niobium and tantalum from each other and from titanium when large amounts of titanium are present. This combination has become of practical importance with the development of MST grade 821 titanium-base alloy containing 2 percent of niobium, 1 percent of tantalum, and 8 percent of aluminum.

It has been shown [3]* that titanium, niobium, and tantalum can be easily separated by anion-exchange in hydrochloric-hydrofluoric acid combinations. Some data are given here for the elution behavior of tin, molybdenum, vanadium, and iron, used as alloying elements in the titanium metal industry, and for phosphorus and tungsten because of their presence in naturally occurring ores or in concentrates. While a question has arisen [1] as to whether it is possible to separate this group of elements from niobium and tantalum, it should be pointed out that present knowledge of the subject indicates that a fairly high concentration of hydrofluoric acid is required to eliminate interfering elements and to retain the niobium and tantalum on the columns for subsequent separation.

The titanium metal alloys are dissolved in a mixture of hydrochloric and hydrofluoric acid and oxidized with a minimum of nitric acid. The solution is transferred to an ion-exchange column containing the strong tetramethylamine anion-exchange resin, Dowex-1. The titanium, and any other interfering elements, are removed by elution with an ammonium chloride-hydrochloric-hydrofluoric acid solution and discarded. The niobium is collected in an eluate containing ammonium chloride and hydrofluoric acid. The tantalum is collected in a separate portion by elution with a slightly acid ammonium chlorideammonium fluoride mixture. Boric acid is added to these eluates to complex the hydrofluoric acid, and the earth acids are then precipitated with cupferron. The cupferron precipitates are ignited to the pentoxides and weighed as $\mathrm{Nb}_{2} \mathrm{O}_{5}$ and $\mathrm{Ta}_{2} \mathrm{O}_{5}$.

The procedure requires 2 to 3 days to carry to

*Figures in brackets indicate the literature references at the end of this paper. completion, as about $12 \mathrm{hr}$ are required for the ionexchange separations, and some time is required for the solution of the sample and the cupferron precipitations.

\section{Apparatus and Resins}

Ion-Exchange Columns. The columns are constructed of polystyrene and are approximately $12 \mathrm{in}$. long and 1 in. i. d. A simple column can be prepared from a 12 -in. length of polystyrene tubing as follows: The bottom of the tube is closed by a waxed No. 5 rubber stopper with a $3 / 16$-in. hole. A 6 -in. length of polystyrene tubing, $3 / 16-i n$. o. d. and $1 / 16$-in. bore, is inserted into the hole flush with the upper surface of the stopper. Another 6-in. length of this tubing is attached to the smaller tube with a 2 -in. length of Tygon R tubing, and the flow controlled by a hose-cock clamp on the Tygon tubing.

If a number of analyses are to be made, it is convenient to arrange the columns so that a number can be operated with a minimum of attention [5]. Plastic columns suitable for such an assembly have been developed [6], and are equipped with "Doletype" fittings of polystyrene. Inlet and outlet tubes are of polyethylene; flexible connections where necessary are made of Tygon $R$ tubing. The flow of solutions is controlled by hose-cock clamps on these flexible connections. The connections should be made and carefully checked in order to avoid any possibility of leakage of the solutions containing hydrofluoric acid. An assembly of this type is illustrated in figure 1.

Resins. Dowex-1, 200- to 400-mesh, 8- to 10 percent divinylbenzene cross linkage are used. Experience over a period of several years has shown that the mesh-size of these resins may vary considerably from lot to lot. To avoid difficulty, the resins as received are air-dried, and sieved through a 270mesh sieve. Material retained on the 270-mesh sieve is used for other purposes. Most of the fines are removed from the fraction passing the 270-mesh sieve as follows: Prepare a suspension of the resin in diluted hydrochloric acid $(1+19) .{ }^{1}$ The coarser

Diluted hydrochloric acid $(1+19)$ denotes 1 volume of cencentrated hydrochloric acid, sp gr 1.18 , diluted with 19 volumes of water. If no dilution is specified, the concentrated analytical reagent is meant. 


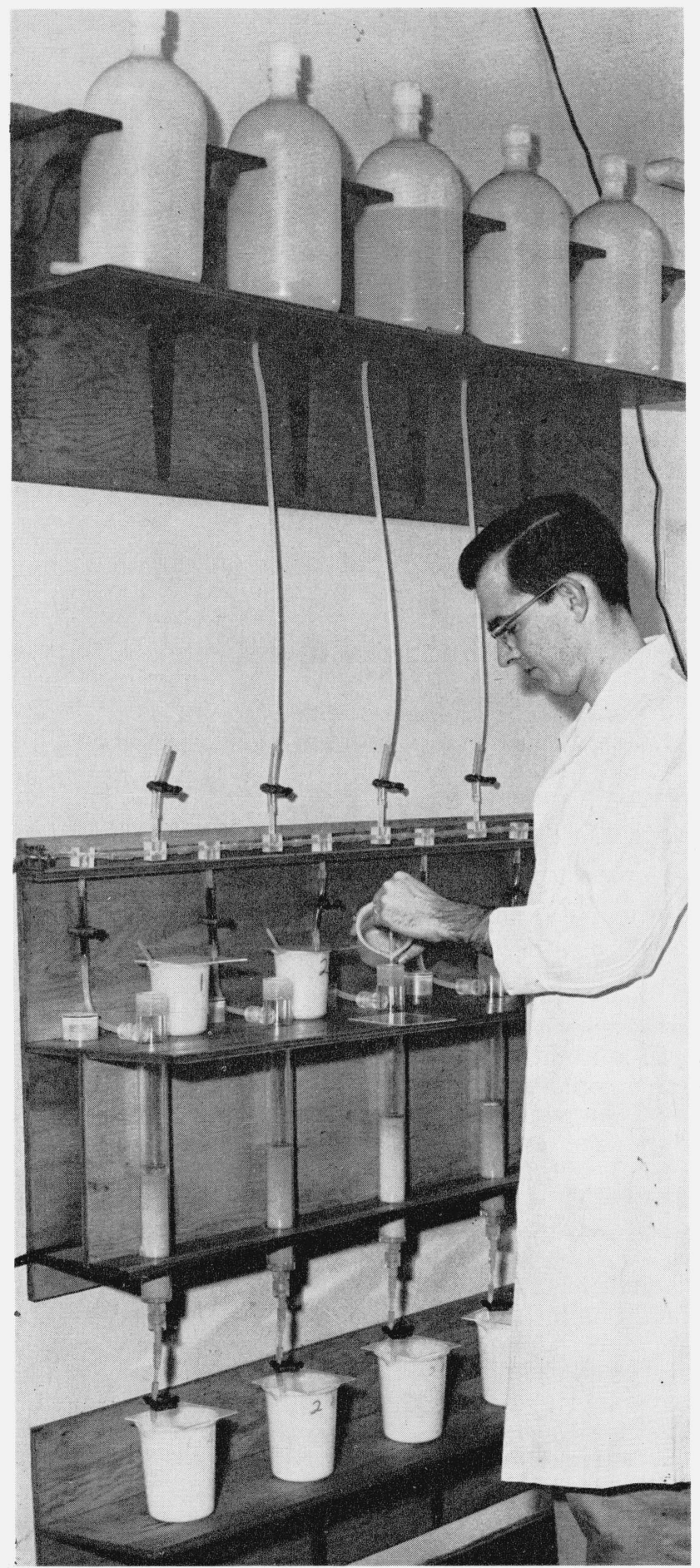

Figure 1. Assembly of ion-exchange columns.

fraction is allowed to settle 10 to $15 \mathrm{~min}$, and the fines removed by decantation. Repeat the process several times: until most of the very fine material is removed from the suspension. Cover the bottom of the ion-exchange column with a $1 / 4^{-}$to $\frac{3}{8}-$ in. layer of acid-resistant vinyl chloride plastic wool. Add portions of the resin suspension to obtain a settled column of the resin 6 to 7 in. high. The loaded column should be run through several cycles of elution with alternate additions of diluted hydrochloric acid $(3+1)$ and diluted hydrochloric acid $(1+9)$ to remove the remainder of the fines. The column is then washed with diluted hydrochloric acid $(1+3)$ and is ready for use. Resin columns prepared in this way have been used for several years; the only maintenance required is to empty and refill the column with the resin charge if the flow rate becomes excessively slow due to packing. The resin charge should not be allowed to become dry.

Polyethylene Ware. 250-ml and 600-ml Griffin form beakers are required. Bottles are used for preparing and dispensing acid mixtures containing hydrofluoric acid.

\section{Reagents}

Hydrochloric-Hydrofluoric Acid Solution. Add 250 $\mathrm{ml}$ of hydrochloric acid to $300 \mathrm{ml}$ of water, then add $200 \mathrm{ml}$ of hydrofluoric acid, dilute to 1 liter with water, and mix well. This solution is referred to as 25-20 mixture in the procedure.

Ammonium Chloride Solution (240 g/liter). Dissolve $240 \mathrm{~g}$ of ammonium chloride in $800 \mathrm{ml}$ of water by warming, and dilute to 1 liter with water. Filter to remove insoluble material. This solution is used as a stock solution in preparing the three solutions which follow.

Ammonium Chloride - Hydrochloric - Hydrofluoric Acid Solution. Transfer $300 \mathrm{ml}$ of ammonium chloride solution, $200 \mathrm{ml}$ of hydrofluoric acid, and $125 \mathrm{ml}$ of hydrochloric acid to a polyethylene bottle. Dilute to 1 liter with water, and mix well. This solution is referred to as $7-12 \quad \frac{1}{2}-20$ mixture in the procedure.

Ammonium Chloride-Hydrofluoric Acid Solution. Transfer $600 \mathrm{ml}$ of ammonium chloride solution and $40 \mathrm{ml}$ of hydrofluoric acid to a polyethylene bottle, dilute to 1 liter with water, and mix well. This solution is referred to as $14-4$ acid mixture in the procedure.

Ammonium Chloride-Ammonium Fluoride Solution. Transfer $600 \mathrm{ml}$ of ammonium chloride solution and $40 \mathrm{ml}$ of hydrofluoric acid to a polyethylene beaker. Adjust the solution to a $p \mathrm{H}$ of 5 to 6 with ammonium hydroxide (approximately 80 to $85 \mathrm{ml}$ will be required), and dilute to 1 liter with water. This solution must be prepared with reasonable care, as a solution which is too acid will not completely elute the tantalum in the volume specified in the procedure. A solution which is too alkaline will precipitate tantalum in the column, spoiling the determination being run and the one which follows. This solution is referred to as 14-4 neutral mixture in the procedure.

Cupferron Solution (60 g/liter). Dissolve $6 \mathrm{~g}$ of cupferron in $90 \mathrm{ml}$ of water, dilute to $100 \mathrm{ml}$, and filter through a dry filter. This solution should be cooled $\left(5^{\circ} \mathrm{C}\right)$ and prepared as needed, as the solution is not stable. 
Cupferron Wash Solution. Add $25 \mathrm{ml}$ of cupferron solution to $975 \mathrm{ml}$ of diluted hydrochloric acid $(1+9)$. Prepare as needed.

\section{Procedure}

As the samples dissolve quite rapidly, the rate of solution can be conveniently controlled by adding the sample to the cooled acid mixture. Transfer $100 \mathrm{ml}$ of the 25-20 mixture to a covered $250-\mathrm{ml}$ polyethylene beaker. Add $5.00 \mathrm{~g}$ of the sample, ${ }^{2}$ in small portions, to the acid until the sample is completely transferred and dissolved. Warm slightly $\left(40^{\circ}\right.$ to $\left.50^{\circ} \mathrm{C}\right)$ on the steam bath, and oxidize the titanium by the dropwise addition of nitric acid. Approximately 1 to $2 \mathrm{ml}$ will be required, and the amount should be kept to a minimum because of the strong replacing power of nitric acid for niobium on the exchange column. Digest on the steam bath for 10 to $15 \mathrm{~min}$, to remove the oxides of nitrogen. Rinse the plastic cover and walls of the beaker with the 25-20 mixture, and dilute the solution to a volume of $150 \mathrm{ml}$ with the same mixture.

Transfer $50 \mathrm{ml}$ of the 25-20 mixture to the column in small increments ( 5 to $10 \mathrm{ml}$ ), and drain the acid to $1 \mathrm{~cm}$ above the resin bed, catching the eluate in a $600-\mathrm{ml}$ polyethylene beaker. Transfer the solution of the sample, prepared according to the directions in the previous paragraph, in small increments $(5$ to $10 \mathrm{ml}$ ) to the column. Add the sample solution as it moves down the column until all the solution has been transferred. Wash the beaker 4 to 5 times with 5 -ml portions of the 25-20 mixture, transferring the washings to the column. Finally wash down the sides of the column several times with approximately $50 \mathrm{ml}$ of the same solution.

Add a total of $300 \mathrm{ml}$ of the $7-12 \frac{1}{2}-20$ mixture at a flow rate of approximately 100 to $125 \mathrm{ml} / \mathrm{hr}$. Allow the solution to drain to the top of the resin, and wash the sides of the column with 4 or 5 portions (a total of about $25 \mathrm{ml}$ ) of the 14-4 acid mixture, allowing the solution to drain to the top of the column each time. Replace the beaker with another 600-ml beaker, and discard the first eluate containing the titanium, vanadium, iron, tin, etc.

Add a total of $300 \mathrm{ml}$ of the 14-4 acid mixture, maintaining the technique and flow rate described in the preceding paragraph. ${ }^{3}$ Wash the sides of the column with approximately 25 to $30 \mathrm{ml}$ of the 14-4 neutral mixture in portions of $5 \mathrm{ml}$. Remove the beaker containing the second fraction, and reserve it for the determination of niobium. Replace the beaker with a $600-\mathrm{ml}$ polyethylene beaker.

Add a total of $350 \mathrm{ml}$ of the 14-4 neutral mixture and reserve the solution for the determination of tantalum. The column is cleaned by the addition, in increments, of $50 \mathrm{ml}$ of diluted hydrochloric acid $(1+3)$, and is then ready for the next sample.

${ }^{2}$ If a smaller weight sample is used, approximately $25 \mathrm{ml}$ of acid mixture should be used for each gram of sample, and an extra 25-ml portion added to maintain the high fluoride concentration required for a satisfactory separation of niobium.

3 This point in the procedure provides a convenient and satisfactory place to stop overnight if the elution is not carried through as a continuous operation.
To the second fraction which contains the niobium, add $15 \mathrm{~g}$ of boric acid, $70 \mathrm{ml}$ of hydrochloric acid, and $80 \mathrm{ml}$ of water. Warm on the steam bath $\left(30^{\circ}\right.$ to $35^{\circ} \mathrm{C}$ ) to dissolve the boric acid. Cool to $5^{\circ} \mathrm{C}$, and add slowly with continuous stirring 30 to $50 \mathrm{ml}$ of cupferron solution. ${ }^{4}$ Add paper pulp, stir well to distribute the pulp, and allow to stand 10 to $15 \mathrm{~min}$. Filter through a double thickness of $9-\mathrm{cm}$ closetextured filter paper fitted to a Büchner funnel and precoated with a little filter pulp. Transfer the precipitate to the funnel, and wash well with $400 \mathrm{ml}$ of cold $\left(5^{\circ} \mathrm{C}\right)$ cupferron wash solution. Transfer the precipitate and paper to a weighed $25-\mathrm{ml}$ porcelain crucible, and ignite at a low temperature until carbon is gone. Finally ignite to constant weight at $1,000^{\circ}$ $\mathrm{C}$, and weigh as niobium pentoxide.

To the third fraction, which contains the tantalum, add $9 \mathrm{~g}$ of boric acid, $85 \mathrm{ml}$ of hydrochloric acid, and $80 \mathrm{ml}$ of water. Warm to dissolve the boric acid, precipitate, filter, wash, and ignite the tantalum as described for niobium. Weigh the tantalum as tantalum pentoxide.

\section{Elution of Elements with Hydrochloric- Hydrofluoric Acid Solutions}

Of the elements that precipitate with cupferron [10], molybdenum and tin have proved to be the most troublesome to remove from the column (with a moderate volume of eluting solution) ahead of the niobium and tantalum. Both have been used as alloying elements for titanium metal, so elution curves covering a range of hydrochloric and hydrofluoric acid concentrations are of interest. The curves for titanium, niobium, and molybdenum have been presented previously [3], and the curves obtained for quadrivalent tin are shown in figure 2 . Curves for phosphorus (as phosphate) are given because it is present in ores and concentrates, and for iron (ferric) because of interest in ferroalloys of niobium and tantalum. As has been shown before $[7,8]$, the retention of niobium and tantalum from solutions containing relatively high concentrations of hydrofluoric acid is good, so satisfactory separations can be obtained in solutions of this type.

Experiments demonstrated that the volume coordinate of the curves could be compressed somewhat by substituting ammonium chloride for a part of the hydrochloric acid. A "clean-up" solution containing 7.2 percent by weight of ammonium chloride, 12.5 percent by volume of hydrochloric acid, and 20 percent by volume of hydrofluoric acid was selected. The behavior of a number of possible interfering elements in this medium is also shown in figure 2. The excellent summary by Kraus and Nelson [9] of the elution behavior of twenty elements in hydrochloric-hydrofluoric acid mixtures containing from 0.5 to $1 \mathrm{~N}$ concentrations (approximately 2 to $4 \%$ by volume) of hydrofluoric acid would suggest, by extrapolation, antimony, bismuth, and

${ }^{4}$ Blank determinations usually amount to less than $0.5 \mathrm{mg}$ when the reagents conform to ACS specifications, and will ordinarily counterbalance the few tenths of a milligram of earth acid lost in the precipitation. 

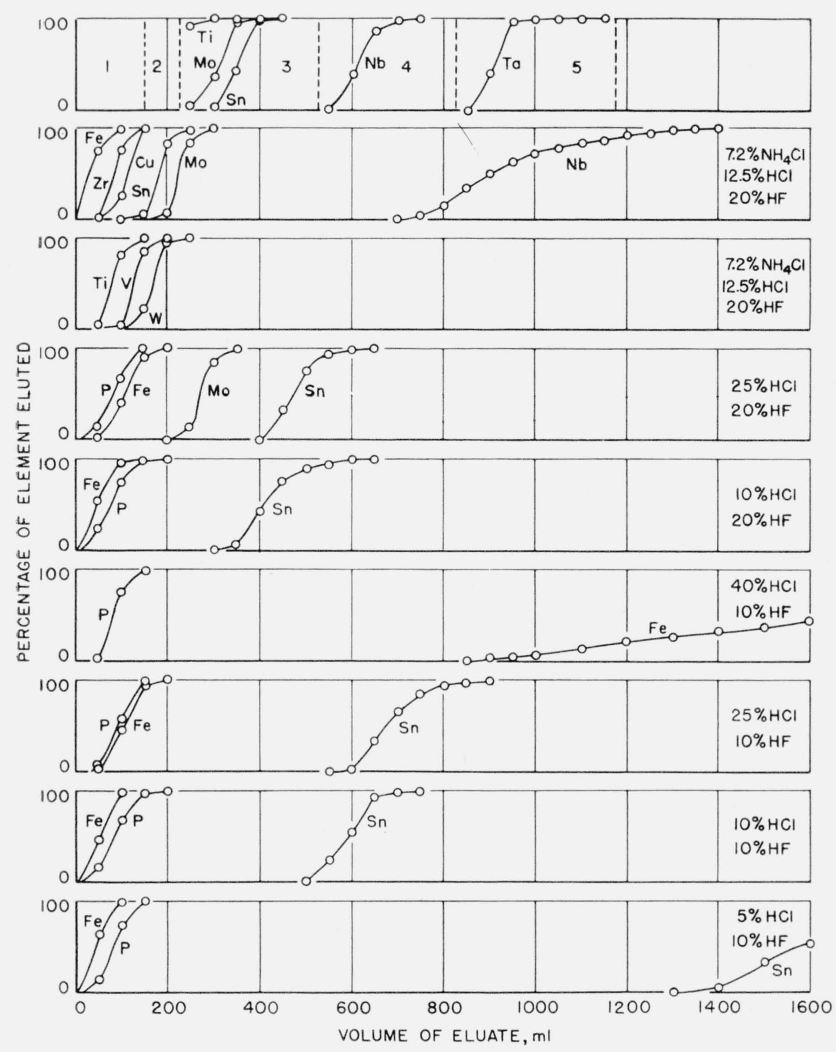

Figure 2. Elution behavior of elements.

thallium as potential interferences. Titanium alloys do not normally contain these elements, and they were not detected by spectrographic examination of the niobium and tantalum oxides obtained in the analysis of the alloys listed in table 2 . Some earth acid ores contain considerable percentages of antimony and bismuth, which are normally removed by sulfide precipitation before the earth acids are isolated for separation.

The behavior of some of the elements during an analysis by the recommended procedure is shown by the first line of elution curves in figure 2. Titanium, molybdenum, and tin are removed well ahead of the niobium fraction. The "tailing" of the tantalum fraction has received notice [2], and preliminary experiments indicate the $p \mathrm{H}$ of the tantalum eluting solution to be an important factor.

\section{Results}

The results obtained by the recommended procedure on a series of synthetic mixtures approximating the composition of the alloys to be analyzed are given in table 1 . These values require little comment, being within the usual limits for gravimetric determinations. The titanium in these mixtures, available as commercially pure titanium metal containing negligible quantities of niobium and tantalum, was dissolved in a hydrochloric-hydrofluoric acid mixture exactly as were the samples. Suitable quantities of niobium and tantalum pentoxides were weighed in a platinum crucible and fused in sodium bisulfate. The cooled fusion was dissolved in the acid mixture containing the titanium, the crucible removed, and the solution oxidized with nitric acid.

This procedure was followed in preparing the mixtures because the high-purity metals were not readily available. Aluminum was not added because it forms a sparingly soluble compound with sodium in the presence of considerable amounts of fluoride. Photometric procedures have been described [4] for the determination of small quantities (20 $\mathrm{mg}$ or less) of niobium and tantalum, and are not included in this paper.

TABLE 1. Results of determinations of niobium and tantalum by the recommended procedure in various synthetic mixtures

\begin{tabular}{|c|c|c|c|c|c|c|c|}
\hline \multirow{2}{*}{$\begin{array}{l}\text { Experi- } \\
\text { ment }\end{array}$} & \multirow{2}{*}{$\begin{array}{l}\text { Tita- } \\
\text { nium } \\
\text { added }\end{array}$} & \multicolumn{3}{|c|}{ Niobium } & \multicolumn{3}{|c|}{ Tantalum } \\
\hline & & Added & Found & $\begin{array}{c}\text { Differ- } \\
\text { ence }\end{array}$ & Added & Found & $\begin{array}{c}\text { Differ- } \\
\text { ence }\end{array}$ \\
\hline $\begin{array}{l}1 \\
2 \\
3\end{array}$ & $\begin{array}{l}9 \\
5 \\
5 \\
5\end{array}$ & $\begin{array}{c}m g \\
24.5_{0} \\
23.9_{1} \\
135.1_{9}\end{array}$ & $\begin{array}{l}m g \\
24.4_{3} \\
23.7_{7} \\
135.1_{2}\end{array}$ & $\begin{array}{c}m g \\
-0.07 \\
-.1_{4} \\
-.07\end{array}$ & $\begin{array}{c}m g \\
175.0_{\mathrm{s}} \\
173.7_{3} \\
20.6_{0}\end{array}$ & $\begin{array}{c}m g \\
174.7_{9} \\
173.5_{7} \\
20.6_{0}\end{array}$ & $\begin{array}{c}m g \\
-0.29 \\
-.1_{6} \\
.0\end{array}$ \\
\hline $\begin{array}{l}4 \\
5 \\
6\end{array}$ & $\begin{array}{l}5 \\
5 \\
5\end{array}$ & $\begin{array}{r}135.2_{2} \\
93.6_{7} \\
93.4_{6}\end{array}$ & $\begin{array}{r}135.1_{2} \\
93.4_{6} \\
93.4_{9}\end{array}$ & $\begin{array}{l}-.10 \\
-.21 \\
+.0_{3}\end{array}$ & $\begin{array}{l}20.3_{5} \\
50.1_{2} \\
48.8_{9}\end{array}$ & $\begin{array}{l}20.4_{7} \\
49.9_{9} \\
48.7_{7}\end{array}$ & $\begin{array}{l}+.1_{2} \\
-.1_{3} \\
-.1_{2}\end{array}$ \\
\hline
\end{tabular}

The results obtained on one commercial and two experimental alloys are given in table 2 . The determinations for each sample were obtained in two or three sets, and show satisfactory precision for gravimetric determinations of these mixtures. One set of niobium and tantalum pentoxide precipitates for each sample was examined spectrographically for impurities. Moderate amounts (estimated at 0.1 percent or less) of boron, silicon, and iron were usually observed. The boron and silicon can be volatilized by treatment with sulfuric and hydrofluoric

TABLE 2. Results of determinations of niobium and tantalum by the recommended procedure in titanium-base alloys

\begin{tabular}{|c|c|c|c|c|c|c|c|c|}
\hline \multirow{2}{*}{$\begin{array}{l}\text { Sample } \\
\text { numner }\end{array}$} & \multirow{2}{*}{$\begin{array}{l}\text { Sample } \\
\text { weight }\end{array}$} & \multicolumn{3}{|c|}{ Niobium } & \multicolumn{3}{|c|}{ Tantalum } & \multirow{2}{*}{ Nominal composition } \\
\hline & & $\begin{array}{l}\text { A verage } \\
\text { value }\end{array}$ & Range & $\begin{array}{l}\text { No. of deter- } \\
\text { minations }\end{array}$ & $\begin{array}{l}\text { A verage } \\
\text { value }\end{array}$ & Range & $\begin{array}{l}\text { No. of deter- } \\
\text { minations }\end{array}$ & \\
\hline $\begin{array}{l}\text { WA-74 } \\
\text { WA-75 } \\
\text { WA-76 }\end{array}$ & $\begin{array}{l}9 \\
5 \\
5 \\
5\end{array}$ & $\begin{array}{r}\% \\
2.01 \\
2.72 \\
0.58\end{array}$ & $\begin{array}{c}\% \\
\text { 2. } 00_{6} \text { to } 2.02_{1} \\
\text { 2. } 71_{1} \text { to } 2.72_{5} \\
0.58_{0} \text { to } 0.58_{2}\end{array}$ & $\begin{array}{l}6 \\
4 \\
4\end{array}$ & $\begin{array}{l}\% \\
1.00 \\
0.39 \\
3.55\end{array}$ & $\begin{array}{c}0.99_{1} \text { tc } 3.00_{4} \\
38_{7} \text { to } 2.39_{1} \\
3.55_{0} \text { to } 3.55_{6}\end{array}$ & $\begin{array}{l}7 \\
5 \\
4\end{array}$ & $\begin{array}{l}\text { Al } 8-\mathrm{Nb} 2-\mathrm{Ta} 1 \\
\text { Al } 4-\mathrm{Nb} 3-\mathrm{Ta} 0.4-\mathrm{Sn} 1 \\
\text { Al } 7-\mathrm{Ta} 3.5-\mathrm{Nb} 0.5-\mathrm{Mo} 2-\mathrm{V} 1.5\end{array}$ \\
\hline
\end{tabular}


acids, but experience over a period of several years has shown that this correction usually amounts to less than $0.2 \mathrm{mg}$. Iron is present due to impurities in the reagents, and is corrected for in the blank determination, amounting usually to no more than 0.2 to $0.3 \mathrm{mg}$. Aluminum, calcium, magnesium, tin, and titanium were occasionally observed in amounts estimated to approach 0.1 percent, but usually in amounts of less than 0.01 percent. Occasionally, traces (estimated at 0.01 percent or less) of silver, chromium, manganese, and lead were reported. These impurity surveys, along with the data in table 1 and figure 2 , confirm the fact that the ion-exchange procedure furnishes a very satisfactory analytical separation.

The authors are indebted to J. E. Griffin, MallorySharon Titanium Corporation, Niles, Ohio; to M. J. Miles of Titanium Metals Corporation, Henderson, Nev.; and to Galen Porter of Metals Research Labs., Electro Metallurgical Corporation, Niagara Falls, N. Y., who furnished the ingots for preparation of the samples WA-74, WA-75, and $\mathrm{WA}-76$. Particular thanks are due to Sam Vigo, Watertown Arsenal Laboratories, Watertown, Mass., whose efforts led to the formation of a task force (with J. L. Hague as chairman) to study the problem as a part of the analytical activities of the Metallurgical Advisory Committee on Titanium.

\section{References}

[1] M. J. Cabell and I. Milner, Anal. Chim. Acta 13, 266 (1955).

[2] M. J. Cabell and I. Milner, Anal. Chim. Acta 13, 264 (1955).

[3] J. L. Hague, E. D. Brown, and H. A. Bright, J. Research NBS 53, 262 (1954) R P2542.

[4] J. L. Hague and L. A. Machlan, J. Research NBS 62, 62, 11 (1959) R P2923.

[5] J. L. Hague, E. E. Maczkowski, and H. A. Bright, J. Research NBS 53, 354 (1954) RP2552.

[6] Silve Kallmann, Ledoux and Co., Teaneck, N. J. (private communication)

[7] K. A. Kraus and G. E. Moore, J. Am. Chem. Soc. 73, 11 (1951).

[8] K. A. Kraus and G. E. Moore, J. Am. Chem. Soc. 73, 14 (1951).

[9] K. A. Kraus and F. Nelson, Symposium on ion exchange and chromatography in analytical chemistry, p. 44 , ASTM Special Technical Publication No. 195 (Philadelphia, Pa., 1958).

[10] G. E. F. Lundell and J. I. Hoffman, Outlines of methods of chemical analysis, р. 118 (J. Wiley \& Sons, Inc., New York, N. Y., 1938).

Washington, D. C., July 10, 1958. 